FedUni ResearchOnline

http://researchonline.federation.edu.au

This is a Submitted Manuscript of an article published by Taylor \& Francis in International Journal of Training Research on 24/07/2015, available online:

http://doi.org/10.1080/14480220.2015.1051351 


\title{
How closely do Australian Training Package qualifications reflect the skills in occupations? An empirical investigation of seven qualifications.
}

\begin{abstract}
This paper uses evidence from an Australian research project into under-recognised skills in occupations, gathered through industry-level interviews and company case studies, to examine VET curricula. The project, funded by the Australian Research Council, focused on skill in jobs traditionally regarded in Australia as unskilled. As part of the project, the evidence about skill was compared with the relevant qualifications. The qualifications are contained in Training Packages, which form the basis of most formal VET training in Australia. The qualifications for the seven occupations were in three broad industry areas (manufacturing, services and property services) and had all been developed in recent decades, unlike apprenticed trades which have long-standing qualifications and curricula in Australia.

The comparison exercise showed some mismatches between the skills that were found in the researched occupations and the content of the qualifications. Some of the issues are believed to have broader applicability beyond these specific occupations and qualifications and thus can provide evidence to improve the design of Training Packages themselves.
\end{abstract}

\section{Keywords}

Training Packages; competency-based training; qualifications development; under-recognised skill

\section{Introduction}

This paper relates how evidence about seven occupations was compared with the relevant qualifications in the Australian VET system, and what was found in that comparison. The process reported in the paper was carried out as part of a major three-year project funded by the Australian Research Council, which examined the skill in jobs traditionally regarded as unskilled. The overarching project was titled 'Recognising the skill in jobs traditionally considered unskilled' and was designed to uncover evidence about skill in jobs considered to be unskilled and how the evidence accorded with perceptions of skill in those jobs. The aim of the project as a whole was to improve public policy relating to training for such occupations.

In Australia, documentation for VET qualifications is grouped into artefacts known as Training Packages, which each cover a particular industry area. The Training Package examination in the project stemmed from an initial belief that under-recognition of skill in jobs might lead to unsatisfactory curriculum for the occupation. It was intended to provide not only data that might improve the qualifications during normal processes of review of the particular Training Packages within which the qualifications were included, but also to have applicability more broadly across Training Packages.

The relevant research question had two parts:

a) How do the perceptions [of skill] affect the nature and quality of VET curriculum as expressed in Training Packages and their delivery?

b) How can the researched evidence improve Training Packages and provide better advice for delivery?

Print (1993) refers to the multitude of stakeholders involved in the different stages of curriculum development and therefore it might be expected that the final negotiated 
compromise might not be viewed as optimal, or even acceptable, by all stakeholders. Training Packages are unlikely to be perfect. But while there have been many critiques of Training Packages, none in recent years has specifically focused on the fit between the qualifications in Training Packages and the occupational role for which the qualifications were developed. In this paper, we show how we used researched evidence about occupations to offer a structured way of examining Training Package qualifications.

\section{Background and literature}

Australian Training Packages are the cornerstone of the current Australian Vocational Education and Training (VET) system and are developed on competency-based principles. Competency-based training (CBT) was first introduced in the VET sector in the late 1980s. Syllabus documents were previously developed and owned by individual training providers including public State systems, known as Technical and Further Education (TAFE). In the early iterations of CBT, these documents were rewritten with a focus on learning outcomes rather than content, assessment became focused on skills rather than knowledge and recognition of prior learning was introduced so that learners did not have to repeat items they already knew or could do (Smith, Hill, Smith, Perry, Roberts, \& Bush, 1996). However, implementation was piecemeal and generally curriculum documents were still owned by individual training providers. In some cases, national modules were developed by industry-specific bodies set up for that purpose. This resulted in a common curriculum was used by a range of training providers; the electrical industry was an example of this.

After the initial period of implementation, it became clear that the CBT system had some weaknesses. Training Packages were introduced from 1997 in an effort to address such weaknesses (Australian National Training Authority, 1996): they were intended to regularise vocational education and training curriculum offerings and bring about national consistency, to make training align more closely with industry competency standards (rather than being mediated through privately-owned curriculum documents) and to make accredited training easier to deliver in a range of environments. They had similarities with the English National Vocational Qualification (NVQ) system (Burke, 1989) but the major difference was that there were no parallel systems of qualifications as there are in England.

Training Packages provide what might be called a 'building block' approach to curriculum development, with units of competency making up qualifications which in turn are contained within the Package (Smith \& Keating, 2003). There are 65 Training Packages containing in total 1600 qualifications (Department of Industry, 2014a). This is a substantial number, but is a reduction over recent years, and a very large reduction from pre-Training Package times. Many Training Packages and qualifications cover industry areas and occupations which, prior to the 1990s, did not have nationally accredited training in Australia. Training Packages are available to anybody to purchase, and the content of Training Packages can be viewed on a national web site (training.gov.au) Thus employers, for example, who wish to use competency standards for training of their workers, do not need to purchase the Training Package unless they wish to have the training accredited. Individuals can inspect the competencies required to operate in an industry and judge whether they would like to be trained, or perhaps to apply for Recognition of Prior Learning in part or all of a qualification.

Each Training Package consists of a number of units of competency (known collectively as competency standards) and instructions as to how they can be packaged to make qualifications. A Package may contain only a few qualifications - for example the current Training and Education Training Package contains only a Certificate IV and a Diploma - or may contain scores of different qualifications. Training Packages generally include some 'imported' units 
from other Training Packages that are recommended for use in the Package. Some of these units are common across many qualifications, for example on customer service or food safety. Training Packages also include guidelines on assessment. Publicly funded support materials (formerly called 'non-endorsed components') are also developed: these include learner guides, resources for teachers and so on (Smith, 2002). Training Packages are essentially 'curriculum' documents, in that they prescribe the content and the assessment of formal VET training, but there has been much resistance to viewing them as curriculum. This matter is discussed in detail in Smith (2002) who refers to an announcement by the Chief Executive Officer of the then Australia National Training Authority in 1997 that curriculum no longer existed following the introduction of Training Packages, a statement that reportedly created a great deal of difficulty subsequently for Training Package developers ${ }^{1}$.

When a new Training Package is to be developed, or an existing one reviewed, a sum of money is allocated to the relevant Industry Skills Council or other relevant body. There are twelve Industry Skills Councils (ISCs) covering most of Australian industry, or at least those industries and occupations that are serviced by VET qualifications. The ISC engages a consultancy firm to carry out the detailed work associated with the Training Package development and review, and convenes a national steering committee with relevant stakeholders. Representatives of training providers used to be excluded from this process, in a rather clumsy attempt to have industry 'own' the process, but have been included now for some years in the recognition that the main use of Training Packages is for training, and therefore the expertise of training professionals is needed.

Training Package development involves extensive consultations with all stakeholders including employers, unions, employer associations and professional bodies. The draft products are then opened to national consultation, and this generally includes face-to-face consultations and posting of draft documents on the ISC's web site with an invitation for any interested people to submit comments. There are strict guidelines as to how the Package is developed and how it looks; these guidelines were first produced in the late 1990s and have changed over time (see http://www.ivet.com.au/a/64.html for a link to the Training Package Development handbook). Once a Training Package has been developed, and has been agreed by representatives from the eight Australian States and Territories, it is formally endorsed in a national process, currently contained within the Department of Education and Training but previously managed by the National Skills Standards Council, which is now defunct. The Package is then placed on 'training.gov.au' and can be delivered, with appropriate 'teach out' arrangements mandates for the older version.

A similar process is followed for reviews of Training Packages, which take place about every five years. Some years ago a new process was introduced where continuous improvement of a Training Package could be undertaken rather than, or in addition to, one-off major reviews every few years (Dawe, 2002). There have been signs that this process is counter-productive, as it is difficult for all involved parties (learners, training providers and employers) to keep track of versions. For training providers, for example, 'administrative burden' is one common complaint, (Department of Industry, 2014a); and version control is a compliance issue identified by the national regulator, the Australian Skills Quality Authority. Apprentices who

\footnotetext{
${ }^{1}$ This argument continues to be raised, for example by participants in 2015 consultations on Training Package reform; one example, from a consultation in Canberra, can be seen at www.vetreform.industry.gov.au/files/senccanberra-morning.pdf
} 
often study for three years or more may have several changes to the content of their training during that time.

Ove the years that there has been considerable opposition to Training Packages (Smith, 2002), both within the sector and among some VET researchers (e.g. Wheelahan, 2008). Opposition is often underpinned by a fundamental disagreement with the notion of competency-based training. Smith \& Keating (2003) have summarised early objections to CBT in Australia as 'philosophical' objections, educational objections and practical problems associated with implementation. West (2004), in relation to National Vocational Qualifications (NVQs), similarly referred to 'technical, 'moral' and 'market' critiques ${ }^{2}$. Smith (2010) combines the two frameworks to provide a four-fold typology of existing critiques of CBT: philosophical critiques; technical defects; pedagogical defects; and centralisation and control. Smith (2010) proposes a fifth critique: lack of teacher capability to work effectively with competency-based training. In other words, by its nature, a competency-based system demands high levels of capability, but these capabilities are missing in the Australian VET workforce. This fifth critique is borne out by a study by Hodge (2014) which showed that many VET teachers had only a limited understanding of how to work with units of competency.

Partly in response to some of the critiques discussed above, in 2003-4 the then Australian National Training Authority carried out a 'high level' review of Training Packages (Schofield \& McDonald, 2004). By 'high-level' it meant fundamental. Consultants were engaged to talk to many stakeholder groups around Australia. Perhaps surprisingly, the report acknowledged some concerns but recorded general and widespread support for the basic premise for, and nature of, Training Packages. The report, however, advocated actions in six areas: (a) closer agreement among stakeholders about what Training Packages are and what they are not; (b) better design of Training Packages; (c) tighter development and review processes; (d) more use of skill sets which are sub-sets of qualifications; (e) more education of teachers, to work more effectively with Training Packages; and (f) clearer pathways into and out of Training Packages (Schofield \& McDonald, 2004, pp. 14-32).

The relevant federal department set in train some work to implement these recommendations. This work was designed to inform the creation of the 'next generation' of Training Packages. However the pace of change was slow on most fronts until 2012, when a process of Training Package 'updates', otherwise known as 'streamlining' began. This was in response to a report known as 'VET Products for the $21^{\text {st }}$ Century' (National Quality Council/Council of Australian Governments Skills and Workforce Development Sub-Group, 2009) which grew out of the Schofield and McDonald report. The main features of the 'update' or 'streamlining' process have been the reduction in length of the unit of competency documents, splitting of the units into two separate parts for (a) specifications (elements of competency and performance criteria) and (b) assessment, and tighter prescription around assessment. During 2013-14 all ISCs worked on these changes, but approval of all Training Packages including updates was halted in early 2014, following the election of a new Federal government in late 2013, and only recommenced in early 2015.

A further review of Training Packages (Department of Industry, 2014a) was issued for consultation in late 2014, which discussed many matters raised in earlier reviews but also canvassed the possibility of more radical and fundamental changes to Training Packages including a new name for them. In addition, another consultation document (Department of

\footnotetext{
${ }^{2}$ Market critiques were related to the penetration of NVQs into the VET qualification market, and do not apply to the Australian context, as the hegemony of the Australian form of CBT has been complete due to the absence of the plethora of awarding bodies that create diversity in the UK VET market.
} 
Industry, 2014b), issued at the same time, proposed 'tendering out' of the development of Training Packages to independent bodies and consultants, instead of the process being managed only by ISCs. The Training Package examination process in this research project was thus carried out at a pivotal time for the future of Training Packages in Australia.

\section{Research method}

The qualifications for the project were selected in consultation with the three relevant Industry Skills Councils as those being most appropriate for the occupations being studied. The occupations were: Hotel reception worker ('Guest service agent'), Cleaner, Security officer, Concrete products operator, Sewing machinist, Waiter, and Retail (non-supermarket) assistant. The project also studied the occupations of Chef and Metal fitter/machinist. These occupations were selected to provide a contrast with occupations that are generally accepted in Australia as being skilled; but these latter occupations are not covered in this paper.

The project as a whole consisted of several phases. Prior to the Training Package examination the following phases were undertaken, during the period 2011-13:

- Interviews with 19 national stakeholders from the VET and industrial relations systems;

- Interviews with 44 targeted senior stakeholders across the nine occupations;

- 19 company case studies with 115 interviews in total; in each company, workers, a supervisor, a human resource or training manager, and a senior manager were interviewed, and each also completed and commented on a set of scales, developed in a pilot project (Smith \& Teicher, 2011) to identify the extent to which the job in question required each of the national employability skills;

- In most of the case studies, workers completed and commented on the 'Spotlight' tool, developed for identifying hidden skills (Hampson \& Junor, 2010);

- Validation of findings with industry forums for each occupation.

In all, around 250 people were interviewed or took part in forums. Each of the four researchers took responsibility for specific occupations and cross-occupational analyses took place at research team meetings. Human research ethics committee approval was obtained for all research fieldwork including the forums.

On advice from the ISCs, the current versions of the Training Packages were used for the examination phase, rather than any draft versions ('updates' and regular cyclical reviews) that were being prepared or were awaiting endorsement at the time. Thus, some of our suggestions and comments may have been anticipated in the newer versions.

Prior to commencing the exercise, which was a desk activity, we consulted with relevant specialist officers from the Industry Skills Councils. In addition, we attended Training Package Update information sessions for the relevant Training Packages. For the desk examination, we asked the following sets of questions of the data:

- From our interviews and case studies: What had we found in our research about the 'technical' and 'non-technical' skills that were needed in the occupation? What skills were required to perform well in the occupation?

- Structure of the qualification: What was the structure of the qualification (e.g. cores, electives, packaging rules)? What streams or electives were most commonly delivered? What was the balance between units relating to 'technical' skills vs units relating to 'non-technical' skills? 
- Comparison with our data: Did the qualification at unit level seem to recognise the skills seen in our research? Were there aspects of skill missing at unit level (and were the units core or elective) and /or within the Units of Competency? Were there skills identified by our research as being necessary to perform well in the role that were not included?

Analyses for each occupation were completed using the headings above, and provided to the three relevant Industry Skills Councils for comment. A planned exercise of consultation with industry stakeholders (many of whom had volunteered at the earlier industry validation forums) on the findings of this Phase did not take place. This was due to advice from the ISCs that industry was being required at the time (late 2014) to provide too much input into VET matters. In early 2015, however, a national stakeholder forum was held which was able to provide some advice on the project including the Training Package examination phase. 20 people attended this forum, including representatives from industry associations and peak bodies, the union movement, training provider peak bodies, ISCs and relevant Federal and State government departments. Findings of the forum were summarised by Misko (2015).

\section{Findings}

The findings are discussed under three main headings. The first presents the findings (derived from analysis of data from the preceding phases of the project) about skill in the occupations. The second section presents the structure of each qualification, and discusses the implications of the structure for a match with the skills we found in the job; and the third discussion provides detailed comparison of our findings with the content within units of competency.

\section{Skill in the occupations}

In each instance, condensed summaries of the findings about the major skills for each occupation were written by the researchers who had researched that occupation, as a prompt for the subsequent analysis. The summaries were based on the extensive fieldwork: five industry-level interviews, between 10 and 20 interviews in the case study companies, and feedback from industry validation forums for each occupation. The summaries were written using structured headings.

An example of such a summary, for the occupation of security officer, follows:

The occupation and context in which it was researched

The job of security officer was researched via:

- Five industry-level interviews,

- Two company case studies including 10 interviews in all-both in large metropolitan companies with a range of different contracts; the security officer and supervisors interviews took place in a city centre shopping centre ('Secure Co') and a museum ('Safeguard Co') respectively, and an

- Industry validation forum attended by eight people including employers and RTOs

What tasks are involved in doing the job?

In the contexts researched, the job involved patrolling premises, responding to instructions from supervisor, dealing with incidents among members of the public, assisting colleagues in incidents, and helping with tasks that were more properly part of the job of those employed in the premises or those visiting, for example (in the shopping centre) assisting with setting up and dismantling exhibits, directing tourists to sites, or (in the museum) helping to control school parties. The security officers used a radio to communicate with each other and their supervisors. The officers needed to record their patrolling e.g. by touch point. They needed to write incident 
reports if anything unusual occurred and could be required to appear in court. From time to time they would need to manage evacuation of the premises, in conjunction with others, and to assist in other emergencies e.g. if a customer had a heart attack.

It was noted that the role researched was only part of the security industry. Participants in all phases of the research pointed out that other roles included: crowd control, aviation security, concierge duties, armed guard for ATM fill-up, and technology-related security work (e.g. CCTV monitoring). However it was stated that the role we researched was typical mainstream security work.

Most security officers seemed to be mature-aged with very few school-leavers involved. Often it was a third or fourth career.

What were the findings from our research about the 'technical' and 'soft' skills that are needed in the occupation?

Much of the work was routine, but with periods of intense activity e.g. medical emergencies or a burst water pipe. The officers needed the ability to instantly read and defuse. Team work was vital. The officers needed to liaise with, and help out, third parties (e.g. shopping centre management and museum management) and 'fourth parties' (e.g. teachers leading school groups and shop owners) at the sites. Writing reports was very important (as it was used for legal cases). The most important skill for the shopping centre officers was seen as defusing situations and talking down aggrieved people. Observation was also noted as an important skill.

However there were also physical skills: fitness, as there was a lot of walking, and the ability to restrain people on the occasions when it was necessary.

Managers tended to rate the job as more skilled than workers did; the job was not well paid but career prospects were good. Personal attributes were viewed, by supervisors and senior management, as very important in hiring staff. Planning and organising were regarded as important by some respondents, but not by all. Judgment was also regarded as important by most.

What skills are required to perform well in the occupation?

Attitude was mentioned by managers as marking out people who were going to succeed and progress in the job. Teamwork and supporting others was also noted by all as being vital to a high level of performance. Communication skills were essential to good performance: 'The most powerful thing is not brawn, it's your mouth.' Also, life experience was regarded as important.

These summaries proved helpful in the examination of the Training Package qualifications, although detailed data were also drawn in from interview transcripts during the process.

\section{Analysis at qualification structure level}

Table 1 shows the structure of the qualifications examined for each of the seven occupations investigated. Each qualification included a set of core units of competency. Students were required to complete all of the core units (with one exception) to a standard of competence. The qualifications all supported a far greater number of elective units, often corresponding to different streams within the occupation. Students were normally required to complete only a relatively small number of the available elective units to complete the qualification. In some cases, electives could be 'imported' or selected from other Training Packages, but these are not shown, for the sake of clarity. Students do not normally select electives; generally the RTO makes a choice about which elective units of offer.

\section{Table 1: Structure of the selected qualifications}




\begin{tabular}{|l|l|l|l|}
\hline Occupation & Qualification & $\begin{array}{l}\text { Number of Core } \\
\text { Units and number } \\
\text { required for study }\end{array}$ & $\begin{array}{l}\text { Number of Elective } \\
\text { Units and number } \\
\text { required for study }\end{array}$ \\
\hline Cleaner & $\begin{array}{l}\text { Certificate III in } \\
\text { Cleaning Operations }\end{array}$ & $4:$ All required & $19: 15$ required \\
\hline $\begin{array}{l}\text { Concrete Products } \\
\text { Operator* }\end{array}$ & $\begin{array}{l}\text { Certificate III in } \\
\text { Manufactured Mineral } \\
\text { products }\end{array}$ & $7:$ Six required** & $114: 14$ required \\
\hline $\begin{array}{l}\text { Guest Service Agent } \\
\text { (Hotel Reception) }\end{array}$ & $\begin{array}{l}\text { Certificate III in } \\
\text { Hospitality }\end{array}$ & $7:$ All required. & $133: 8$ required. \\
\hline $\begin{array}{l}\text { Retail Sales Assistant } \\
\text { (non-supermarket) }\end{array}$ & $\begin{array}{l}\text { Certificate III in Retail } \\
\text { Operations }\end{array}$ & $6:$ all required & $41: 8$ required. \\
\hline Security Officer & $\begin{array}{l}\text { Certificate III in } \\
\text { Security Operations }\end{array}$ & $8:$ All required & $11: 6$ required. \\
\hline Sewing Machinist & $\begin{array}{l}\text { Certificate III in } \\
\text { Clothing Production }\end{array}$ & $5:$ All required & $104: 14$ required. \\
\hline Waiter & $\begin{array}{l}\text { Certificate III in } \\
\text { Hospitality }\end{array}$ & $7:$ All required & $133: 8$ required. \\
\hline
\end{tabular}

* Note (i): Within the job of concrete product operator, there are two distinct job roles: Batchers, in the 'pre-mix' arm of the industry, who oversee the mixing of different ingredients to produce 'wet concrete'; and people who work in 'pre-cast' concrete plants, carrying out a range of processes creating and using moulds to produce items like drains and freeway bridges. The latter people are generally referred to as 'concrete labourers'

** Note (ii) Five are compulsory, and the sixth is a choice between 'Make measurements' and 'Read dials and indicators'.

What is immediately noticeable from Table 1 is the relatively small number of core units in each of the qualifications compared to the number of electives. The high number of electives was a reflection in many instances of the different jobs that are covered by the occupational qualification. Thus the Certificate III in Hospitality covered two occupations in the project Hotel Receptionist and Waiter - but also many others; hence the presence of 133 elective units. The high number of electives in many of the qualifications prevented the team from examining each of the units at a detailed level. To get around this problem, we attempted to find out the frequency with which different units within qualifications were actually delivered, in order to obtain a picture of what was a 'typical' learner pattern that could then be analysed. However we were unable in most cases to obtain this information, as training providers were not required to report numbers of learners except where public funding was involved, and so the national VET data collections were not of use. We asked the Industry Skills Councils for advice, but they did not keep data on this matter, and even when we did obtain some data in a few instances, it did not appreciably help to unravel the complexity of the enrolment patterns in the qualifications and the reasons for the complexity.

In all instances, the skills we found in the seven occupations through our fieldwork (and summarised in the manner of the Security Officer example above) were recognisable somewhere in the respective qualifications. But perhaps worryingly, some of the major skills uncovered in our fieldwork were not included in the core units of the qualification for the occupation. Sometimes the core units represented a mix of quite general skills whilst the specific skills necessary for performing the tasks in the occupation were contained in the electives. Our analysis of the skills required in each of the seven occupations had shown that the critical skills that employers and workers identified as necessary for the job included a mix 
of both 'technical' and 'non-technical' skills ${ }^{3}$. For example, in the case of retail sales assistant, the occupational analysis showed that interpersonal skills such as the ability to "read" a customer's intention were critical to effective sales work. However, the more technical skills of detailed product knowledge, ability to use the computerised sales equipment, ordering the correct inventory were also just as important to effective sales. Nevertheless, the qualification for the occupation, Certificate III in Retail Operations, did not place the latter 'technical' skills in the core, but only in the elective streams. The core contained only 'non-technical' skills.

But the answer is not so simple as reconfiguring qualifications to ensure that that core units better represent the core skills required. In some instances the sheer number and diversity of the occupational groupings that were covered by the qualification would prohibit a common core of units that would apply to all occupations. An example of this complexity was provided by the Certificate III in Hospitality. This covered two occupations in the study - guest service agent and waiter - but also many others. In the qualification, the seven core units focused on skills such as teamwork and customer service, and general knowledge of the hospitality industry. The elective units were organised into streams for the different occupational areas within hospitality and then groups of electives were recommended for actual occupations such as bar attendant, waiter, guest service agent etc. As a result, the relatively small number of core units in these qualifications industry. The particular skills required for the job were to be found in the large number of electives in the qualification. While there was a logic to this, it meant that the qualification title (Certificate III in Hospitality) did not convey much meaning about the occupation that was being learned (for instance, waiter). A similar effect obtained in concrete products operator. In this case, the qualification covered a range of diverse occupations well beyond the concrete industry, and was not immediately recognisable as relating to the two job roles that we studied, each of which had a small group of units of competency that related to the respective role.

The complexity of the qualifications structures was thus identified as a major issue. Although this did not apply to all of the qualifications (for example, cleaner and security officer qualifications were relatively simple), the majority were complicated to analyse, even though each researcher had worked with Training Packages for many years, so it might be assumed that teachers and learners alike would also find them difficult to navigate. Employers' lack of understanding is perhaps made explicit in the facts that, over the years, governments at national and State/Territory level have funded several programs to enable training providers to work with and interpret Training Packages to employers, and that a unit of competency has been developed for VET teachers to explain them to employers.

\section{Analysis at unit of competency level}

When drilling down to unit level, it was apparent that while there was generally broad coverage of the technical skills involved in the job, sometimes this was rather 'under-done'. For example, in concrete, the unit MSAPMSUP101A Clean workplace or equipment did not specifically address the specialised skills needed to clean concrete equipment, which was an important and integral part of the job. There was a reference to 'specialised cleaning procedures' in one of the elements of competency, but this was not elaborated upon, thus providing no guidance to the trainer or assessor. For concrete batchers, the unit PMC552060C Batch mix concrete did not specifically refer to skills or knowledge about computer-based batching systems, which were ubiquitous in the industry. Another example

\footnotetext{
${ }^{3}$ After much thought, we used the term 'non-technical' to cover what are sometimes known as 'soft', 'generic' or 'employability' skills. This term was validated by the final stakeholder forum.
} 
was security, where the unit on 'managing conflict through negotiation' included reference to defusing situations, which we found to be a fundamental part of the job, but provided no content on how to undertake this task, beyond vague words such as 'appropriate techniques'.

Non-technical skills were often described in the units in general terms (such as 'communication' or 'teamwork') and could have had more explication. For example, a performance criterion from the unit of competency SITHIND301 Work effectively in hospitality service was 'Provide quality customer service, using appropriate methods and techniques to meet customer expectations of quality presentation and timeliness of delivery'. This was very vague, and passed a great deal of responsibility onto the assessor. Such wording perhaps indicated an intention to allow application of the unit in a range of contexts, but in the end it provided no guidance to the learner, teacher or assessor about appropriate methods, levels of customer expectation and so on. Sometimes, crucial aspects of performance were included in the 'critical aspects of evidence' which guide assessment, but were not reflected in the elements of competency or lists of skills and knowledge in the units; in other words, they were not required to be taught.

Integration of skills, including issues of work flow, was found, in the fieldwork, to be important in the jobs we studied. However, it was not consistently present in the units in the qualifications. An example is the core unit for concrete 'batchers'. These workers manage the mixing of the correct proportions of the raw materials so that the product meets the requirements of the customer in terms of viscosity, strength and other features. The unit of competency PMC552060C Batch mix concrete did not detail the range of people that the batchers interacted with at different stages of the process (within and external to the concrete plant), the constant need for quality checking, and the urgency associated with the work. Specifically, the unit of competency for concrete truck drivers assumes that the drivers negotiate with end-users, but our research found that in fact it is the batchers who undertake this complex and often fraught process. Similarly for guest service agents the units did not adequately reflect the stress associated with reception desk work nor the need to evaluate customer behaviour.

It was difficult to get a sense of what a 'good' worker should be doing, from the qualifications and the units. Yet the fieldwork provided many examples where the performance of a 'good' or proficient worker was well described. For example, a proficient waiter was described as ‘choreographing a dance' which could readily be 'translated' for insertion into a unit of competency; and for sewing machinists it was noted that such workers operated at maximum speed for extended periods of time without mishaps. These qualities and attributed were not represented in the qualification or units; in other words, 'aspiration' was missing from the qualifications. This matter goes well beyond the possibility of using grading in competency-based training (Richards, 2014) and could be addressed by the inclusion of statements within each qualification and unit about what is involved in 'good' performance by an experienced worker.

The language of units of competency was found to be misleading. On the one hand, the language used implies complete mastery of the particular skill or job tasks. On the other hand, our research had indicated that in all of the occupations, an extended period of time at work (e.g. six months to twelve months for concrete batchers) was necessary before the job could be done appropriately, and longer for performance to become fluent. 


\section{Discussion}

Our findings, detailed above, were analysed for those with the greatest policy and practice implications, and then translated into the following questions.

a. Do we need to rethink what goes into the core and the elective streams in qualifications, so that industry can expect a particular 'product'? And if so, how?

b. Do qualifications need to be more closely linked to occupations, for example should there be a qualification for 'waiter' rather than a generic Hospitality Certificate III with streams?

c. Can non-technical skills be more fully identified and addressed?

d. How can a Training Package qualification address and encourage good performance?

e. Can expectations for assessment be included more explicitly?

These questions arise from specific matters identified in the qualifications which we studied, but also have applicability across Training Packages in general.

The questions were presented to the national stakeholder forum which concluded the research project. The forum included representatives from the three Industry Skills Councils involved as well as others involved, or having an interest in, Training Package development and review. Attendees included representatives from peak employer and employee bodies, Commonwealth and State government departments, peak training provider bodies, industry associations, a national VET research centre, and two individual researchers in the area. Verbal feedback from the attendees indicated that they agreed with the general thrust of the analysis presented to them and provided in this paper.

With relation to the need for qualifications to be more identifiably attached to occupations, one comment, supported by several attendees, was that this was unlikely to be feasible as there were already a large number of qualifications. Another comment was that the occupations studied in this project might not, in any case, be regarded by some as genuine 'occupations', unlike trade occupations. There was agreement that it was difficult, in Training Packages as they currently stood to articulate some non-technical skills that were difficult to put into words. It was also stated that there was confusion about what were 'soft' skills, as so many different terms were utilised. There was support for the point that Training Packages cannot produce fully competent workers, with a comment that employers seem to expect them to be able to do so, which breeds some discontent among employers. However there was no explicit advice about whether identification of 'good' performance might assist with this dilemma. The questions on core and elective units, and on assessment did not receive attention due to time constraints. These two questions have clear policy and practice possibilities, and could be raised in other forums.

Approval was voiced for the research project's method for uncovering and analysing skills in occupations. Some ISC representatives stated that in Training Package development and reviews, they only had time to talk to representatives of industry and other stakeholders, not to visit companies and talk to workers. However others said that they did attempt to visit companies.

Analysis of the project data led us to a proposition that the content of qualifications may both reflect negative perceptions of skill in the occupation and also affect negative perceptions of skill in the jobs. In this way, the undervaluing of skill in these occupations could be seen as the crucial element in a vicious circle. Perhaps the strongest example of this happening was in 
retail where the fieldwork indicated very little demand by employers for qualified workers, and also not a great deal of respect for the qualifications where workers were qualified. It is acknowledged, however, that the latter could be due to training delivery or other issues, rather than the content of the Training Package. There was little support from the stakeholders for the contention that complexity of the qualifications might discourage adoption of qualifications. Attendees suggested other reasons for low take-up of qualifications, such as the transience of workforces in some of the occupations. However, the disparity in take-up of qualifications among the occupations studied suggest that this is an area worthy of further study.

A limitation of the project data is that we looked only at jobs that are traditionally regarded as unskilled or low-skilled. This means that our findings cannot necessarily be extrapolated to qualifications for jobs which are highly-regarded in terms of skill levels required. One might assume that the qualifications for the latter occupations, having had the benefit of longer periods of development and more powerful stakeholders, might be fuller and better reflect the skill in the relevant job; however we did not research this matter.

\section{Conclusion}

It should be reiterated that in general, we found that, based on those qualifications that we studied, Training Packages generally succeed quite well in capturing most skills involved in the occupations that they seek to train for, as might be expected considering the broad consultation that takes place. However, in our analysis we focused rather on improvements that might be made and hence the tone of our discussion may appear more negative than warranted.

An important point that emerged quite late in the project is the methodological confirmation, by stakeholders at the national forum, that our project method would be helpful for them in Training Package consultations, should resources be available. In other words, qualitative fieldwork, particularly talking to workers, provides unique insights into a job. This is hardly a novel concept, and similar methods of developing curriculum have long been identified and listed in the literature on competency-based training (for example, Harris, Guthrie, Hobart \& Lundberg, 1995). Yet the processes are generally not followed in Training Package development and review. It is possible that this fact may account for less than optimal curriculum in qualifications which have only been developed since the advent of Training Packages, including those in our study; occupations whose qualifications pre-dated Training Packages, such as those for the apprenticed trades, may have the advantage of a pre-existing curriculum based on sounder principles.

The findings indicate that Training Package qualifications are not always successful in representing, and therefore guiding training for, the non-technical skills that are present in all jobs, but are more crucial in some jobs than others, particularly (but not only) in jobs with a high degree of contact with the public, as did five of the seven occupations in the study. Structurally, there does not seem to be an easy answer about how to distribute units of competency relating to technical skills and those relating to non-technical skills across the core and elective units of qualifications; nor (in a related point) about how to combine occupations into fewer numbers of qualifications without losing the occupational identity of qualifications.

At a unit level, we found that some units were incomplete in that they did not capture everything that was needed to carry out the task implied in the unit title; but at the same time, the essentiality of the tasks became lost in a sea of words. Perhaps, as we suggest above, a more descriptive picture of the work involved in carrying out essential tasks in a qualification might be provided, including its performance at a proficient level. In this way, it could also be more honestly acknowledged that successful achievement of units of competency cannot be expected to indicate full proficiency at work. 
Some, if not all, of these matters have been debated for a long time in Australia and elsewhere, yet our research showed that the problems remain. The current national review of Training Packages offers an opportunity to reconfigure Training Packages to take account of such issues, and the stakeholder forum outcomes confirmed support for addressing some of the questions posed as a result of the research.

\section{References}

Australian National Training Authority (ANTA). (1996). Training Packages in the national training framework, ANTA, Brisbane.

Burke, J. (1989). The implementation of NVQs. In J. Burke (Ed.) Competency-based education and training. Falmer, London, 109-131.

Dawe, S. (2002). Focussing on generic skills in Training Packages. National Centre for Vocational Education Research (NCVER), Adelaide.

Department of Industry. (2014a). Review of Training Packages and accredited courses Discussion paper, October 2014. Department of Industry, Canberra.

http://vetreform.industry.gov.au/publication/review-training-packages-and-accreditedcourses-discussion-paper

Department of Industry (2014b). Industry engagement in Training Package development Towards a contestable model, Discussion paper, October 2014.. Department of Industry, Canberra.

Harris, R., Guthrie, H., Hobart, B. \& Lundberg, D. (1995). Competency-based education and training: Between a rock and a whirlpool. Macmillan, Melbourne.

Hampson, I. \& Junor, A. (2010). Putting the process back in: Rethinking service sector skill, Work, Employment and Society, 24(3), 527-545.

Hodge, S. (2014). Interpreting competencies in Australian vocational education and training: Practices and issues. NCVER, Adelaide.

Misko, J. (2015). Recognising skill in jobs traditionally considered unskilled: what stakeholders say. A report on the national stakeholder consultation, February 2015. NCVER, Adelaide.

National Quality Council/Council of Australian Governments Skills and Workforce Development Sub-Group. (2009). VET products for the $21^{\text {st }}$ century. NQC Secretariat, TVET Australia, Melbourne.

Print, M. (1993). Curriculum development and design ( $2^{\text {nd }}$ edn.). Allen \& Unwin, St. Leonards, NSW.

Richards, J. (2014). An old chestnut revisited: Teachers' opinions and attitudes toward grading within a competency based training framework. International Journal of Training Research, 12 (3), 182-191

Schofield, K. \& McDonald, R. (2004). Moving on: Report of the high level review of Training Packages. Australian National Training Authority, St. Leonards, NSW. 
Smith, E. (2010). A review of twenty years of competency-based training in the Australian vocational education and training system. International Journal of Training \& Development, 14(1), 54-64.

Smith, E. (2002). Training Packages: Debates around a new curriculum system. Issues in Educational Research, 12(1), 64-84.

Smith, E., \& Keating, J. (2003). From training reform to Training Packages. Social Science Press, Tuggerah Lakes, NSW.

Smith, E. \& Teicher, J. (2011). Ways of seeing: Reconceptualising skills. Service Skills Australia, Sydney.

http://www.serviceskills.com.au/ways-of-seeing-reconceptualising-skills

Smith, E., Hill, D., Smith, A., Perry, P., Roberts, P., \& Bush, A. (1996). The availability of competency-based training in TAFE and non-TAFE settings in 1994. Australian Government Publishing Service, Canberra.

West, J. (2004). Dreams and nightmares: The NVQ Experience. Working paper No. 45, Centre for Labour Market Studies, Leicester, UK.

Wheelahan, L. (2008). Can learning outcomes be divorced from processes of learning? Or why training packages make very bad curriculum. In VET in Context: 11th Annual Australian Vocational Education and Training Research Association Conference, April, Adelaide. 